\title{
Relationship between Ankle Range of Motion (ROM), Muscle Strength, Balance, and Fall Risk in Postmenopausal Women: A Pilot Study
}

\author{
Haripriya $S^{a}$, Veena K. R. Bhagavan ${ }^{b}$, Naina Maharjan ${ }^{c}$ \\ ${ }^{a}$ Associate Professor, Department of Physiotherapy, Laxmi Memorial College of Physiotherapy, \\ Mangalore, India \\ ${ }^{\mathrm{b}}$ Assistant Professor, Department of Obstetrics and Gynecology, AJ Institute of Medical Sciences and Research \\ Center, Mangalore, India \\ ${ }^{c}$ Post Graduate Student and Presenting Author, Laxmi Memorial College of Physiotherapy, Mangalore, India \\ Corresponding Author: Naina Maharjan
}

\begin{abstract}
Menopause is an age-dependent physiological condition associated with a natural decline in estrogen levels, which causes a progressive decrease in muscle mass and strength, and bone density. Estrogen deficiency occurring during menopause will affect both the gynecological area and the whole body which will directly act on skeletal muscle through estrogen receptors. Although various factors are associated with falls in menopausal women, impaired balance and mobility have been consistently identified as the main risk factors.

Identification of the factors associated with balance and fall risk may enable therapists to design treatments to help reduce the risk of falls and the consequences. Since the impact of impaired balance and fall risk among postmenopausal women is undefined. The purpose of this study was to assess the relationship between ankle range of motion and muscle strength with balance and fall risk in post-menopausal women. The ankle ROM and muscle strength were examined by using a universal goniometer and push-pull hand-held dynamometer respectively; the balance was assessed by Y balance test (YBT) and fall risk was measured by Fall Efficacy Scale International (FES-I). Karl Pearson correlation coefficient was used to find the relationship between ankle ROM, ankle strength, balance, and fall risk among postmenopausal women which showed a low positive correlation between the ankle ROM and YBT whereas a
\end{abstract}

moderate positive correlation between the ankle strength and YBT which was statistically significant. The correlation between FES-I and ankle ROM and ankle strength were high and moderate respectively which was also statistically significant.

Keywords: Postmenopausal women, ankle range of motion, ankle strength, balance, fall risk, YBT

\section{INTRODUCTION}

The loss of muscle mass begins substantially at the age of 50 and continues afterward with similar gender-independent changes, such as increased inflammation and satellite cell senescence, reduced myocyte regeneration and protein synthesis, and several other gender-dependent alterations caused by the age-associated decrease of sex hormones. ${ }^{[1,2]}$ Due to the decrease of testosterone in men and estrogens in women, people of both genders experience sarcopenia. Although in general, men show a greater decay in muscle mass, women frequently present with sarcopenia, since their muscle mass level at a young age is physiologically much lower. ${ }^{[3,4]}$

In women, the age-related decline of skeletal muscle mass and strength accelerates with the beginning of menopause. ${ }^{[5]}$ Women tend to lose muscle strength around the 5th and 6th decades of 
age ${ }^{[6,7]}$ As such, some studies showed that women experience a $21 \%$ decrease in strength between the age of 25 and 55 years. ${ }^{[8]}$ As with muscle mass, the loss of muscle strength appears to be concurrent with the occurrence of menopause. ${ }^{[6,9-12]}$ Some authors suggested that the loss of muscle strength coincides with the estrogen deficit of menopause. ${ }^{[9,10-11]}$ The decrease in muscle strength can play a detrimental role in physical function impairments, such as rising from a chair, walking speed, climbing stairs, and the capacity to recuperate after a loss of balance. ${ }^{[13-17]}$

It has been well established that there is a decrease in ROM with age from birth until early adulthood. ${ }^{[18]}$ Although elderly men and women without health problems demonstrate large changes in ankle ROM, women show greater agerelated declines than men do. It is believed that decreased ankle ROM may require altered movement patterns, and these altered movement patterns may compromise balance, thus limiting functional activities such as ambulation. Furthermore, decreases in postural control may result from the use of motions at the hip or trunk that is required to compensate for restrictions in motion at the ankle. ${ }^{[19]}$ Grimston et al. and Vandervoort et al. reported that an average decrement of ankle joint ROM with aging was greater in females than males. ${ }^{[20,21]}$

A recent study also demonstrated the significant decline in balance performance between the ages of 40 and 60 for women, using tests of postural stability. ${ }^{[22]}$ Although various factors are associated with falls, impaired balance and mobility have been consistently identified as the main risk factors. ${ }^{[23]}$ Furthermore, a range of foot and ankle characteristics that may not be considered to be "foot problems"- such as foot posture, range of motion (ROM), and strength are associated with balance but have not yet been evaluated as potential fall risk factors. ${ }^{[24]}$

The primary aim of this study was to examine the relationship between the ankle range of motion and ankle strength with balance and fall risk in postmenopausal women. Considering the fact that the relationship is less clear in postmenopausal women who are not yet in the geriatric age group, the results thus established can help to devise therapeutic strategies to prevent adverse events like falls and fractures in this group particularly in those who are not under hormone therapy.

\section{MATERIALS AND METHODS}

A cross-sectional study was carried out in a tertiary care hospital in Mangaluru, India within approximately one year. 15 subjects selected by convenience sampling method were included in the study. Ankle range of motion (plantarflexion, dorsiflexion, inversion, and eversion) of the right lower limb was measured by a universal goniometer. The ankle strength (plantarflexion, dorsiflexion, inversion, and eversion) was assessed using a push-pull handheld dynamometer. The Y-Balance Test-Lower Quadrant was used to measure the balance after calculating the composite score according to the formula \{ (sum of all three directions $) /($ limb length $\times 3)\} \times 100$. ${ }^{[25]}$ The Falls Efficacy Scale International (FESI) questionnaire was used to estimate the fall risk among the subjects.

Women who were aged 45-65 years, at least 12 months since last menstruation of natural causes, and who were willing to participate in the study were included in the study. Participates with an ankle sprain, swelling, lower extremity injury, fracture or surgery of lower limb, severe musculoskeletal disorders like ankylosing spondylosis and rheumatoid arthritis, neurologic disease like stroke, Alzheimer's disease, Parkinson disease, visual problem or vestibular diseases like BPPV and labyrinthitis, subjects who had undergone surgeries like hysterectomy, those under hormone therapy and subjects who were currently using an assistive device were excluded from the study.

Statistical method: Karl Pearson's correlation coefficient was used to 
Haripriya S et.al. Relationship between ankle range of motion (ROM), muscle strength, balance, and fall risk in postmenopausal women: a pilot study

determine the relationship between ankle ROM, ankle strength, balance, and fall risk among postmenopausal women. The level of significance was set at $5 \%$ to measure the correlation of ankle ROM and muscle strength with balance and fall risk in the study subjects.

\section{RESULTS}

Table 1: Age-wise distribution of the study participants

\begin{tabular}{|c|c|c|}
\hline Age (in years) & Frequency & Percent \\
\hline $45-47$ & 2 & 13.3 \\
\hline $48-50$ & 9 & 60.0 \\
\hline $51-53$ & 2 & 13.3 \\
\hline $54-56$ & 2 & 13.3 \\
\hline Total & $\mathbf{1 5}$ & $\mathbf{1 0 0 . 0}$ \\
\hline
\end{tabular}

Table 2: Correlation of ankle range of motions and ankle strengths with YBT and FES -I.

\begin{tabular}{|c|c|c|c|c|c|c|c|c|}
\hline $\begin{array}{c}\text { Outcome } \\
\text { measures }\end{array}$ & \multicolumn{3}{|c|}{ Range of motions ( ROM ) } & \multicolumn{5}{|c|}{ Ankle Strengths } \\
\cline { 2 - 9 } & PF & DF & IV & EV & PF & DF & IV & EV \\
\hline YBT & -.069 & .122 & -.006 & .102 & .291 & .161 & .406 & .343 \\
\hline FES - I & $.851^{* *}$ & $.675^{* *}$ & $.636^{*}$ & .428 & .413 & .219 & $.554^{*}$ & .268 \\
\hline \multicolumn{8}{|c|}{} & $* *$ Correlation is significant at the 0.01 level (2-tailed). \\
\hline & *. Correlation is significant at the 0.05 level (2-tailed). \\
\hline
\end{tabular}

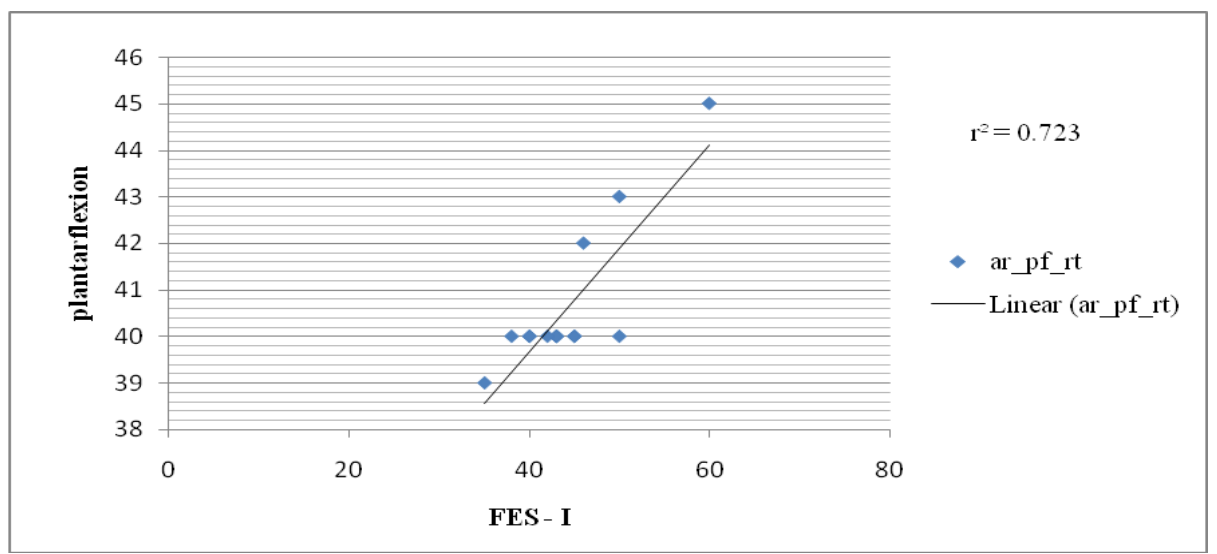

Figure 1: Scatter diagrams of plantarflexion(ROM) and FES-I.

*ar_pf_rt = ankle ROM, plantarflexion



Figure 2: Scatter diagrams of dorsiflexion (ROM) and FES*ar_df_rt = ankle ROM, dorsiflexion

The mean age (in years) of the study participants was 49.7 years with a standard deviation of 3.1 years. The minimum age is 45 years and the maximum age is 56 years. It is observed that $9(60 \%)$ of the individuals are in the age group of 48 to 50 years (Table 1). Very low negative to low positive correlation was observed between the ankle range of motions and YBT shown in Table 2. Table 3 represents a low to a moderately positive correlation between the ankle strength and YBT. High Positive correlation was observed between plantarflexion and FES - I ( $\mathrm{r}=+0.851)$ and was statistically very highly significant $(\mathrm{p}<0.001)$ as presented in Table 4. Also, dorsiflexion was found to be moderately positively correlated with FES $\mathrm{I}(\mathrm{r}=+0.675)$ and was statistically highly significant $(\mathrm{p}<0.01)$. A moderate positive correlation was observed in Table 5 between 

postmenopausal women: a pilot study

ankle strength and FES - I-I $(\mathrm{r}=+0.554)$ and $\quad$ was statistically significant $(\mathrm{p}<0.05)$.

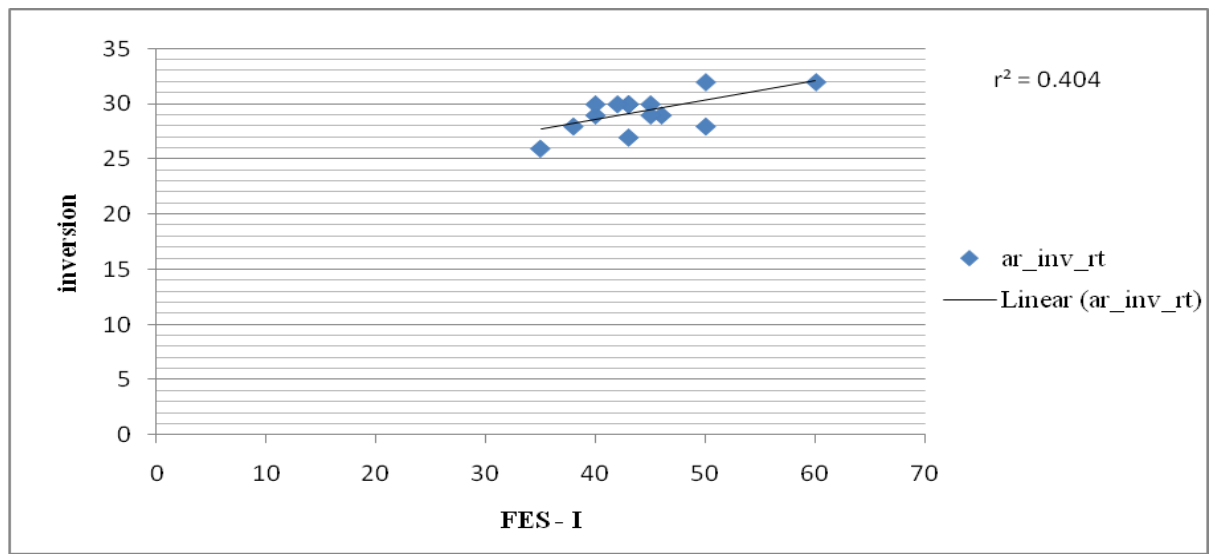

Figure 3: Scatter diagrams of inversion (ROM) and FES-I

*ar_inv_rt = ankle ROM, inversion



Figure 4: Scatter diagrams of inversion (strength) and FES - I

*ar_inv_rt $=$ ankle ROM, inversion

\section{DISCUSSION}

The cross-sectional study was designed to find the relationship between ankle ROM, ankle strength, balance, and fall risk among postmenopausal women who had never received hormone therapy considering that studies have found that hormonal repositioning improves postural balance and probably muscular strength in postmenopausal women. ${ }^{[6,26]}$ Ankle ROM was measured by a goniometer, ankle strength by push-pull hand-held dynamometer, balance by the YBT, and fall risk by FES-I. FES-I with ankle ROM and ankle strength had a strong and moderate correlation, respectively. Range of motion in lower extremities has been seen to reduce with age, and impairment of balance in healthy older adults has been related to muscle weakness and impairment of ROM in the ankle. ${ }^{[27,28]}$ It has been postulated that all ankle movements play a major role in maintaining balance.

The significant difference in normative values for the 50-59-year-old group and the older groups, as well as a moderate correlation with other balance and gait measures, has been seen in scores of the LQ-YBT, in previous studies, indicating that it may be used for assessment of dynamic balance in healthy women 50-79 years old. ${ }^{[29]}$ Allet et al. found an association between deficits in plantar flexor strength and walking during self-selected speeds and suggested that this weakness influences joint movements and muscle power that are important for balance and gait speed. ${ }^{[30]}$ But in the present study, the YBT and lower limb strength in each muscle were poorly or moderately correlated in postmenopausal women, and also, the lower limb muscle strength of the study group was significantly low in this age group. 
In males, lower limb strength declines gradually, whereas in females it declines sharply after menopause. ${ }^{[32]}$ Knee flexor and ankle dorsiflexors are involved in lifting the lower limb during the swing phase of gait, thereby allowing sufficient clearance of the toes over the ground; which is important in the prevention of tripping. $[31,33]$ On the contrary, Spink et al. reported that age-related changes of foot problems are common and it impairs balance and increases the risk of falls. Particularly, hallux plantarflexor strength and ROM of ankle inversion-eversion were the variables most frequently associated with the balance and functional ability in older people. ${ }^{[34]}$ Plantarflexors have a role in supporting the weight of the body and providing stability at the ankle and feet for standing and gait, whereas dorsiflexor muscles against gravity during the swing phase of gait clear the feet from the floor. MacGilchrist et al. suggested that fall risk; a variable related to balance control, is attributed to decrease ankle dorsal flexion strength and decreased walking speed. ${ }^{[35]}$

Falls are particularly related to early postmenopausal estrogen deficiency. ${ }^{[36,37]}$ Early menopause can cause estrogen deficiency, which can disrupt the nervous system's regulation of body balance. FES-I have been shown to be highly correlated with fall risk in postmenopausal women. ${ }^{[38]}$ In a previous study, $28.8 \%$ of postmenopausal women aged $\geq 50$ years reported falls in the previous year. ${ }^{[39]}$ In the same study, among the clinical balance measures, the FES-I was the best independent predictive factor for future falls with a cut-off score of $\geq 26$ points.

In the present study, the FES-I result observed in postmenopausal women shows a significant correlation between all the variables of ankle range of motion. The findings in the present study also indicate a highly significant correlation between FES$\mathrm{I}$ and plantarflexion $(\mathrm{r}=+0.851)$ and a moderate positive correlation with FES-I $(\mathrm{r}=+0.675)$ which was statistically highly significant. The ROM data was collected in the knee extended position, as this position is used in functional situations that challenge balance. Balance and ankle ROM was not substantially correlated, thus indicating that a short gastrocnemius muscle length may not be the cause for decreased ROM at the ankle. The reduced balance performance associated with restricted ankle ROM is probably due to capsules, ligaments, and other non-contractile tissues, or due to post-menopausal sarcopenia or osteoporosis.

The present study provides new insight about risk factors associated with balance and fall risk in post-menopausal women and brings attention to the need to educate the study population on the importance of engaging in physical activity to improve and maintain a healthy aging process. Identification of risk factors can help devise prevention and treatment strategies that will prevent the study population from self-restriction and help them to be independent as age progresses.

\section{LIMITATIONS}

There are some drawbacks to this research that should be considered. Firstly, the entire participant who took part was right-footed and the assessment was done on the right foot. Secondly, it was conducted between groups of relatively healthy and independent postmenopausal women aged 45 to 65 years, and these results cannot be generalized to all older women.

Further studies to evaluate postural balance and its relationship to falls are warranted as they are important for developing preventive and successful interventions as well as improving postmenopausal women's quality of life.

\section{CONCLUSION}

The present study concluded that the postmenopausal women in this study demonstrated a relationship between ankle ROM, muscle strength, balance, and fall risk. Evaluation of postural balance and its relationship to falls is foremost for developing preventive and successful 
interventions as well as improving postmenopausal women's quality of life.

Acknowledgement: We would like to express our sincere gratitude to the study participants.

Conflict of Interest: No conflicts of interest.

Source of Funding: No financial support for the research and/or authorship.

\section{Ethical Approval: Approved}

\section{REFERENCES}

1. Bentzinger, C.F.; Rudnicki, M.A. Rejuvenating aged muscle stem cells. NatMed 2014, 20, 234-235.

2. Anderson, L.J.; Liu, H.; Garcia, J.M. Sex differences in muscle wasting. AdvExp MedBiol 2017, 1043, 153-197.

3. Churchward-Venne, T.A.; Breen, L.; Phillips, S.M. Alterations in human muscle protein metabolism with aging: Protein and exercise as countermeasures to offset sarcopenia. Biofactors 2014, 40, 199-205.

4. Janssen, I.; Heymsfield, S.B.; Wang, Z.M.; Ross, R. Skeletal muscle mass and distribution in 468 men and women aged 18-88 yr. J. ApplPhysiol 2000, 89, 81-88.

5. Maltais, M.L.; Desroches, J.; Dionne, I.J. Changes in muscle mass and strength after menopause. J. Musculoskelet Neuronal Interact. 2009, 9, 186-197.

6. Phillips SK, Rook KM, Siddle NC, Bruce SA, Woledge RC. Muscle weakness in women occurs at an earlier age than in men, but strength is preserved by hormone replacement therapy. ClinSci (Lond) 1993; 84:95-8

7. Samson MM, MeeuwsenIB, Crowe A, Dessens JA, Duursma SA, VerhaarHJ. Relationships between physical performance measures, age, height and body weight in healthy adults. Age Ageing 2000; 29:235-42.

8. Asmussen E, Heeboll-Nielsen K. Isometric muscle strength of adult men and women. In: E. Asmussen, Fredsted A, Ryge, E, Editor. Communications from the Testing and Observation Insitute of the Danish National Association for Infantile Paralysis. Copenhagen: 1961. P
9. Calmels P, Vico L, Alexandre C, Minaire P. Cross-sectional study of muscle strength and bone mineral density in a population of 106 women between the ages of 44 and 87 years: relationship with age and menopause. Eur J Appl Physiol Occup Physiol 1995; 70:180-6.

10. Carville SF, Rutherford OM, Newham DJ. Power output, isometric strength, and steadiness in the leg muscles of pre-and postmenopausal women; the effects of hormone replacement therapy. Eur J Appl Physiol 2006;96:292-8.

11. Samson MM, MeeuwsenIB, Crowe A, Dessens JA, Duursma SA, VerhaarHJ. Relationships between physical performance measures, age, height, and body weight in healthy adults. Age Ageing 2000;29:235-42.

12. Skelton DA, Phillips SK, Bruce SA, Naylor $\mathrm{CH}$, Woledge RC. Hormone replacement therapy increases isometric muscle strength of adductor pollicis in postmenopausal women. ClinSci (Lond) 1999;96:357-64

13. BasseyEJ, Fiatarone MA, O’Neill EF, Kelly M, Evans WJ, LipsitzLA.Leg extensor power and functional performance in very old men and women.Clin Sci (Lond) 1992; 82:321-7.

14. Skelton DA, Greig CA, Davies JM, Young A. Strength, power and related functional ability of healthy people aged 65-89 years. Age Ageing 1994;23:371-7.

15. Alexander NB, Schultz AB, Ashton-Miller JA, Gross MM, Giordani B. Muscle strength and rising from a chair in older adults. Muscle Nerve Suppl1997;5:S56-9.

16. Jette AM, Jette DU. Functional and behavioral consequences of sarcopenia. Muscle Nerve Suppl 1997;5:S39-41.

17. Schultz AB, Ashton-Miller JA, Alexander NB. What leads to age and gender differences in balance maintenance and recovery? Muscle Nerve Supp11997;5:S60-4

18. Boone DC, AzenSP 1979 Normal range of motion of joints in male subjects. JBoneJointSurgAm 61: 756-759

19. Mecagni C, Smith JP, Roberts KE, O'Sullivan SB. Balance and ankle range of motion in community-dwelling women aged 64 to 87 years: a correlational study. PhysTher. 2000 Oct 1; 80(10): 1004-11.

20. Grimston SK, Nigg BM, Hanley DA, Engsberg JR. Differences in ankle joint 
complex range of motion as a function of age. FootAnkle 1993; 14: 215-22.

21. Vandervoort AA, Chesworth BM, Cunningham DA, Paterson DH, Rechnitzer PA, KovalJJ. Age and sex effects on mobility of the human ankle. J Gerontol 1992; 47: M17-21. 11

22. Low Choy N, Brauer S, Nitz J. Changes in postural stability in women aged 20-80 years. J Gerontol A BiolSci Med Sci. 2003; 58A: M525-M530.

23. Shumway-Cook A, Brauer S, Woollacott M. Predicting the probability for falls in community-dwelling older adults using the Timed Up \& Go Test. Phys Ther. 2000 Sep 1; 80(9): 896-903.

24. MenzHB, Morris ME, Lord SR. Foot, and ankle risk factors for falls in older people: a prospective study.J Gerontolo A Biol Sci Med Sci. 2006 Aug 1;61(8):866-70.

25. Filipa A, Byrnes R, Paterno MV, Myer GD, Hewett TE. Neuromuscular training improves performance on the star excursion balance test in young female athletes. J Orthop Sports Phys Ther. 2010; 40(9): 551558.

26. Naessen T, Lindmark B, Lagerström C, Larsen HC, Persson I. Early postmenopausal hormone therapy improves postural balance. Menopause. 2007; 14(1): 14-9.

27. Bok SK, Lee TH, Lee SS. The effects of changes of ankle strength and range of motion according to aging on balance. Ann Rehabil Med. 2013 Feb; 37(1): 10.

28. Amundsen LR. Effects of age on joints and ligaments. In: Kauffman TL, editor. Geriatric rehabilitation manual. New York: Churchill Livingstone; 1999. p. 14-6.

29. Freund JE, StettsDM, Oostindie A, Shepherd J, Vallabhajosula S. Lower Quarter Y-Balance Test in healthy women 50-79 years old. JWomenAging. 2019 Nov 2;31(6):475-91.

30. Allet L, Armand S, de Bie RA, Golay A, Pataky Z, Aminian K, et al. Clinical factors associated with gait alterations in diabetic patients. Diabet Med 2009;26(October (10)):1003-9

31. DohertyTJ. Invited review: Aging and sarcopenia. J ApplPhysiol (1985). 2003;95 (4):1717-27.
32. Hughes VA, FronteraWR, Roubenoff R, Evans WJ, Singh MA. Longitudinal changes in body composition in older men and women: role of body weight change and physical activity. Am J ClinNutr. 2002;76 (2):473-81.

33. Macrae PG, Lacourse M, Moldavon R. Physical performance measures that predict faller status in community-dwelling older adults. J Orthop Sports PhysTher 1992;16: 123-8

34. SpinkMJ, FotoohabadiMR, Wee E, Hill KD, Lord SR, MenzHB. Foot and ankle strength, range of motion, posture, and deformity are associated with balance and functional ability in older adults. ArchPhysical MedRehabil. 2011 Jan 1;92(1):68-75.

35. MacGilchrist C, Paul L, Ellis BM, Howe TE, Kennon B, Godwin J. Lower-limb risk factors for falls in people with diabetes mellitus. Diabet Med 2010;27(February (2)):162-8.

36. Crilly. R.G., Richardson, L.D., Roth, J.H., Vandervoort, A.A., Hayes,K.C. \& Mackenzie, R.A. (1987) Postural stability and Colles' fracture. Age and Ageing, 16, 133-138

37. Winner SJ, Morgan CA, Evans JG. Perimenopausal risk of falling and incidence of distal forearm fracture.BMJ. 1989 Jun 3; 298(6686):1486-8.

38. F. Hita-Contreras, A. Martínez-Amat, R. Loma-Vega, P. Álvarez, A. Aránega, E. Martínez-López, N. Mendoza, Predictive value of stabilometry and fear of falling on falls in postmenopausal women. Climacteric 16 (5) (2013) 584-589.

39. Ersoy Y, MacWalter RS, Durmus B, Altay ZE, Baysal O. Predictive effects of different clinical balance measures and the fear of falling on falls in postmenopausal women aged 50 years and over. Gerontology. 2009;55(6):660-5

How to cite this article: Haripriya S, Veena K. R. Bhagavan, Maharjan N. Relationship between ankle range of motion (ROM), muscle strength, balance, and fall risk in postmenopausal women: a pilot study. International Journal of Science \& Healthcare Research. 2021; 6(3): 291-297. DOI: https:// doi.org/ 10.52403/ijshr.20210751 